\title{
The alkali metal occurrence characteristics and its release and conversion during wheat straw pyrolysis
}

\author{
Yufeng Zhang ${ }^{\text {a, b }}$, Xingyun Xie ${ }^{\text {a, c }}$, Jing Zhao ${ }^{\text {a, b }}$, Xiaolin Wei ${ }^{\text {a, b, * }}$ \\ a State Key Laboratory of High-Temperature Gas Dynamics, Institute of Mechanics, Chinese Academy of Sciences, Beijing, 100190, China \\ b School of Engineering Science, University of Chinese Academy of Sciences, Beijing, 100049, China \\ ${ }^{\mathrm{c}}$ North China Electric Power University, Baoding, Hebei, 071003, China
}

\section{A R T I C L E I N F O}

\section{Article history:}

Received 22 May 2019

Received in revised form 30 October 2019

Accepted 4 November 2019

Available online 5 November 2019

\section{Keywords:}

Wheat straw

Release

Conversion

Potassium

\begin{abstract}
A B S T R A C T
Biomass is an abundant and clean resource with good application value. However, due to high contain of alkali metals, it causes boiler's corrosion and slagging during utilization. In this paper, pyrolysis experiments were carried out from 200 to $1000^{\circ} \mathrm{C}$ and a series of detection methods are applied to explore occurrence, release and conversion characteristics of wheat straw. When temperatures are raised from 200 to $1000^{\circ} \mathrm{C}$, water-soluble $\mathrm{K}$ releases first. Then $\mathrm{NH}_{4} \mathrm{Ac}$ soluble $\mathrm{K}$ converts to water-soluble $\mathrm{K}$. It is found that $\mathrm{NO}_{3}^{-}$content is high, which accounts for $27.11 \%$ of total anions. At low temperatures $\left(<400^{\circ} \mathrm{C}\right)$ $35.50 \% \mathrm{~K}$ will release as $\mathrm{KNO}_{3}$, which is larger than that of the solid fuels with less $\mathrm{NO}_{3}^{-}$. Meanwhile part of $\mathrm{K}$ and $\mathrm{Cl}$ enriches on particles surface due to carrying of moisture. When temperatures are higher than $400{ }^{\circ} \mathrm{C}, \mathrm{K}$ is mainly released in the form of $\mathrm{KCl}$. As $\mathrm{KCl}$ on the sample surface is released, $\mathrm{K}$ and $\mathrm{Cl}$ inside the sample can't reach the sample surface. At $600^{\circ} \mathrm{C}$, the total $\mathrm{KCl}$ content increases to the maximum. Furthermore it is found that $\mathrm{NH}_{4} \mathrm{Ac}$ soluble $\mathrm{K}$ can convert into water-soluble $\mathrm{K}$. When it is $800^{\circ} \mathrm{C}, \mathrm{K}$ release is $53.66 \%$. And $\mathrm{K}$ release accounts for $55.26 \%$ at $1000{ }^{\circ} \mathrm{C}$.
\end{abstract}

() 2019 Elsevier Ltd. All rights reserved.

\section{Introduction}

Wheat is a cereal crop widely cultivated all over the world, which is one of the three major cereals, and its caryopsis is one of the major staple foods of human beings. It is also one of the most important food crops in China. Currently, wheat is widely grown in 23 provinces in China and the area planted with wheat is more than 24 million hectares with a production of 131.44 million tons in 2018. Due to the large amount of wheat planted, the production of wheat straw is also huge. Wheat straw production per year is about $1.8 \times 10^{9} \mathrm{t}$. Therefore, wheat straw as a biomass has the characteristics of stable source and huge reserves and effective utilization of wheat straw can greatly alleviate the fossil energy crisis [1,2] and improve environmental pollution problems [3-5]. However, the alkali metal elements (mainly $\mathrm{K}$ ) in wheat straw are rich and mainly in the form of inorganic salts [6,7]. Since the alkali metal inorganic salts have low melting points, they are easily released during pyrolysis or combustion [8-11]. When the wheat straw is heated, part

\footnotetext{
* Corresponding author. State Key Laboratory of High-Temperature Gas Dynamics, Institute of Mechanics, Chinese Academy of Sciences, Beijing, 100190 China.

E-mail address: xlwei@imech.ac.cn (X. Wei).
}

of the alkali metal will release, causing corrosion of the boiler furnace [12-15]. The gaseous alkali metal will condense, adsorb and deposit on the heated surface of the boiler furnace, causing problems such as fouling and scaling of the furnace, which seriously affects the heat transfer of the boiler [16-21]. These problems cause serious obstacles to the development and utilization of wheat straw [22-26]. If we can clarify the occurrence, the transformation and release mechanisms at different temperatures of alkali metals, we can more effectively purify the gas during the combustion and pyrolysis of wheat straw. Wheat straw will be used more reasonably and effectively $[27,28]$.

Velizar et al. [29] perform a cross-flow washing of wheat straw and beech wood chips. Based on the experimental results, a model of the leaching process of alkali metals and alkaline earth metals is established. Wang et al. [30] study the effect of surface temperature of $\mathrm{Fe}-\mathrm{Cr}-\mathrm{Ni}$ alloy probe on the condensation of alkali metal vapor during wheat straw burning. It is found that when the temperature reached $815^{\circ} \mathrm{C}$, a large amount of $\mathrm{K}$ was released in the form of $\mathrm{KCl}$. Li et al. [31] study the effects of wheat straw and temperature on the release and transformation of alkali metals during the mixed combustion of coal and S-rich straw. The results show that the mixed effects of $\mathrm{Fe}, \mathrm{Ti}, \mathrm{S}, \mathrm{Si}$ and $\mathrm{Al}$ can reduce the amount of $\mathrm{K}$ and $\mathrm{Na}$ released during the co-firing process. Wu et al. [32] co-fired corn 
stalks with coal and measured the ash content. The results indicate that the addition of $\mathrm{Ca}$ reduces the release of $\mathrm{HCl}(\mathrm{g})$ and leads to more release of $\mathrm{KCl}(\mathrm{g})$ and $\mathrm{KOH}(\mathrm{g})$. The experiments were operated under different mass blending fraction and temperature conditions. Liu et al. [33] used the laser induced breakdown spectroscopy (LIBS) to detect the mixture of Zhundong coal and corn stover to study the release characteristics of alkaline materials during co-firing. It was found that the higher the proportion of biomass in the blend, the earlier the peak concentration of the alkaline substance appeared and the peak concentration of sodium decreased and potassium increased. Jonathan et al. [34] use a macro-TGA (thermogravimetric analyzer) reactor to burn softwood and wheat straw at two temperatures $\left(700^{\circ} \mathrm{C}\right.$ and $\left.1000^{\circ} \mathrm{C}\right)$, collected residual ash and analyzed its elemental composition. The results show that at $700^{\circ} \mathrm{C}$, the release of potassium occurs mainly in the coke combustion process. However, when the temperature is raised to $1000^{\circ} \mathrm{C}$, potassium has begun to be released with volatiles in the absence of combustion. Zhang et al. [35] study the conversion and migration characteristics of $\mathrm{K}$ in wheat straw-coal mixed combustion in a laboratory-scale BFB (bubbling fluidized bed) reactor. The results show that as the temperature increases, the reaction between the bed material and the wheat straw is promoted, resulting in the enrichment of $\mathrm{K}$ in the bottom phase. At higher combustion temperatures, $\mathrm{K}$ is predominantly in the form of an aluminosilicate.

The above scholars have studied occurrence or release characteristics of alkali metals in different types of biomass. But the relationship between the occurrence and release characteristics of alkali metals has not been well established. It is worth emphasizing that the release characteristics of alkali metals are closely related to their occurrence. Alkali metals with different occurrence have different release characteristics. In addition to this, for the same occurrence of alkali metal, such as water-soluble alkali metals, different release characteristics are also observed due to that the different anions combine with them. Therefore, in this experiment, the occurrence of alkali metals in wheat straw was first obtained. Wheat in China is mainly grown in the northern region. In order to study the transformation and release characteristics of alkali metals in wheat straw, a typical sample (the wheat straw in northwestern Shandong Province) was selected as the research object. The samples were subjected to industrial analysis and elemental analysis. Then, the microwave digestion experiments and the chemical extraction experiments were carried out. The alkali metals forms and content in wheat straw were obtained through inductively coupled plasma atomic emission spectrometry (ICP-AES). And the relative content of different kinds of inorganic salts of alkali metals (mainly $\mathrm{K}$ ) is obtained according to the different anions and cations concentration and the charge balance. Finally, pyrolysis experiments at different temperatures $\left(200-1000^{\circ} \mathrm{C}\right)$ were carried out to obtain the characteristics of alkali metal release at different pyrolysis temperatures. X-ray photoelectron spectroscopy (XPS), Xray diffraction (XRD), and the scanning electron microscope-energy dispersive spectroscopy (SEM-EDS) were used to analyze the samples obtained by pyrolysis. At different temperatures, the release of alkali metals, the total and surface content of $\mathrm{K}^{+}$and $\mathrm{Na}^{+}$ were obtained. By carrying out experiments and analyzing the experimental results, the occurrence form of $\mathrm{K}$ in wheat straw is obtained and the relationship among the different forms of occurrence, different kinds of alkali metal salts and the release characteristics is established.

\section{Experimental}

\subsection{Experimental materials}

In this paper, the wheat straw is selected from the northwestern part of Shandong Province of China as the research object. The straw is dried at $105^{\circ} \mathrm{C}$ for $3 \mathrm{~h}$ and then ground. The straw powder is sieved, which has a particle size of less than $0.56 \mathrm{~mm}$ is selected as the experimental sample. The samples are then subjected to proximate analysis and ultimate analysis. The results are shown in Table 1.

\subsection{Experimental procedures}

The result of alkali metal content in wheat straw is obtained by microwave digestion experiment. Then, chemical extraction experiments are carried out and three types of extraction solutions (deionized water, ammonium acetate $\left(\mathrm{NH}_{4} \mathrm{Ac}\right)$ and hydrochloric acid $(\mathrm{HCl})$ ) are used to extract the alkali metal. To ensure that each extraction solution was able to thoroughly extract the corresponding form of alkali metal, the samples in extraction solutions were continuously stirred at $60^{\circ} \mathrm{C}$ for $24 \mathrm{~h}$ in each set of experiments. The alkali metals are divided into four forms: water soluble (WS), $\mathrm{NH}_{4} \mathrm{Ac}$ soluble (NACS), $\mathrm{HCl}$ soluble (HS), and acid insoluble (NS). The specific chemical extraction experimental procedure is shown in Fig. 1 [36]. The concentration of various anions and cations in the filtrate was then detected by ICP-AES. The relative amounts of various types of alkali metal salts are obtained.

Then, the effects of different temperatures on the release and conversion of alkali metal were studied and the temperature range was from 200 to $1000^{\circ} \mathrm{C}$. The experimental system is shown in Fig. 2, which consists of a gas supply system, a horizontal furnace, a temperature control system, and a gas analyzer. The length of the furnace is $1000 \mathrm{~mm}$ and the inner diameter is $60 \mathrm{~mm}$. To control the constant pyrolysis temperature, a thermocouple is installed in the middle of the furnace and temperatures are controlled by a temperature control system. For each set of experiments, the tube furnace is heated to the predetermined temperature under the nitrogen atmosphere. Then, $3 \mathrm{~g}$ raw sample, which had not been subjected to chemical extraction experiments, was placed in the middle of the furnace and the furnace was kept at the constant temperature for $10 \mathrm{~min}$ to ensure that the sample was sufficiently pyrolyzed. The gas generated by pyrolysis was introduced into a gas analyzer for analysis. The fully pyrolyzed sample was cooled in the nitrogen atmosphere and weighed. Finally, the samples are analyzed by the XPS, the XRD, and the SEM-EDS. The changes in alkali metal content and morphological characteristics of the sample surface were observed by the SEM-EDS.

\subsection{Detection methods}

\subsubsection{Inductively coupled plasma-atomic emission spectrometry} (ICP-AES)

ICP-AES is a spectral analysis method that uses an inductively

Table 1

Proximate and ultimate analysis of Wheat Straw.

\begin{tabular}{|c|c|c|c|c|c|c|c|c|c|}
\hline \multicolumn{4}{|c|}{ Proximate analysis (\%) } & \multicolumn{6}{|c|}{ Ultimate analysis (\%) } \\
\hline $\mathrm{M}_{\mathrm{ad}}$ & $\mathrm{A}_{\mathrm{ad}}$ & $\mathrm{V}_{\mathrm{ad}}$ & $\mathrm{FC}_{\mathrm{ad}}$ & $\mathrm{C}_{\mathrm{ad}}$ & $\mathrm{H}_{\mathrm{ad}}$ & $\mathrm{O}_{\mathrm{ad}}$ & $\mathrm{N}_{\mathrm{ad}}$ & $\mathrm{S}_{\mathrm{ad}}$ & $\mathrm{Cl}_{\mathrm{ad}}$ \\
\hline 2.74 & 9.28 & 59.32 & 28.66 & 41.82 & 5.21 & 39.44 & 0.80 & 0.12 & 1.05 \\
\hline
\end{tabular}




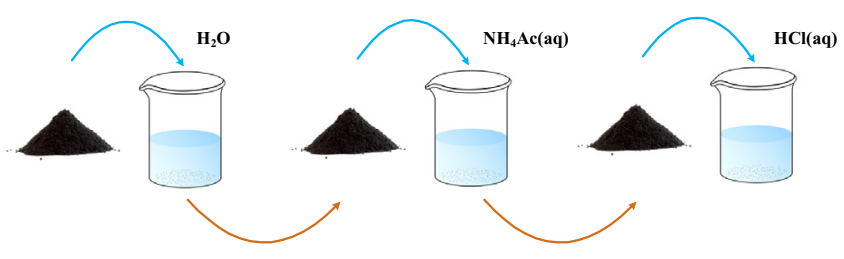

Fig. 1. Chemical extraction experiments flow chart.

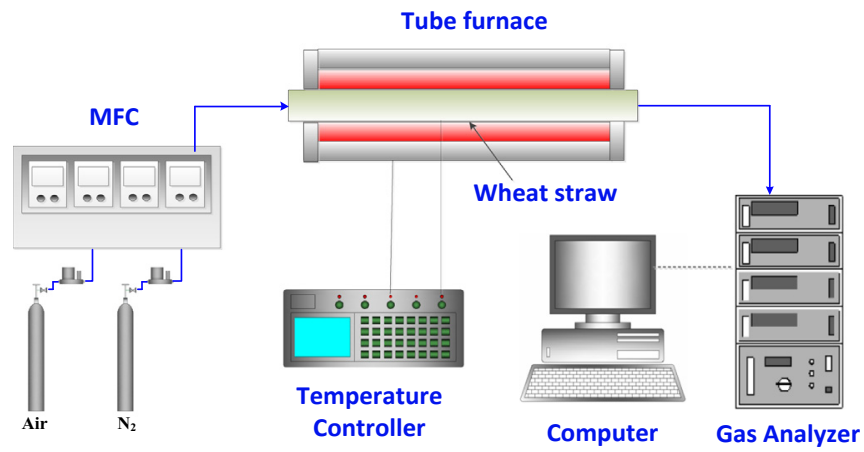

Fig. 2. The horizontal tube furnace experimental system.

coupled plasma moment as an excitation source. It has the advantages of high accuracy, high precision, low detection limit, fast measurement, wide linear range and simultaneous measurement of various elements. In the experiment, ULTIMA2 type ICP-AES was used, which determined the wavelength of $\mathrm{Ca}$ to select $\lambda=317.93 \mathrm{~nm}$ and the detection limit was $\mathrm{DL}=0.003 \mu \mathrm{g} / \mathrm{mL}$. The wavelength of $\mathrm{Mg}$ was determined to be $\lambda=279.08 \mathrm{~nm}$, the detection limit was $\mathrm{DL}=0.02 \mu \mathrm{g} / \mathrm{mL}$. The wavelength of $\mathrm{Na}$ was selected to be $\lambda=589 \mathrm{~nm}$ and the detection limit was $\mathrm{DL}=0.02 \mu \mathrm{g} /$ $\mathrm{mL}$. The wavelength of $\mathrm{K}$ was determined to be $\lambda=766.49 \mathrm{~nm}$ and the detection limit DL was $0.06 \mu \mathrm{g} / \mathrm{mL}$. The wavelength selected by $\mathrm{P}$ was determined to be $\lambda=213.62 \mathrm{~nm}$ and the detection limit DL was $0.05 \mu \mathrm{g} / \mathrm{mL}$. The instrument error rate is less than $1 \%$.

\subsubsection{X-ray diffraction (XRD)}

XRD is a research method for obtaining a diffraction pattern of a sample (biomass) by X-ray diffraction and analyzing the spectrum to obtain information on the composition of the sample, the structure or morphology of internal atoms or molecules. Rigaku D/ $\mathrm{MAC} / \max 2500 \mathrm{v} / \mathrm{pc} \mathrm{X}$-ray diffraction analyzer was adopted as the experimental instrument with voltage of $40 \mathrm{kV}$, current of $200 \mathrm{~mA}$, scanning mode of $\theta / 2 \theta$ coupled continuous scanning, scanning angle range of $5^{\circ}-80^{\circ}$. The angle deviation is $\pm 0.1^{\circ}$. The diffraction energy spectrum was processed and analyzed by Jade 6.0 software.

\subsubsection{Scanning electron microscopy-energy dispersive spectrometer (SEM-EDS)}

SEM-EDS can obtain the alkali metal content and morphological characteristics of the material surface. The high-resolution field emission scanning electron microscope (SEM) uses the Czech Tescan Tescan Mira 3. The EDS uses an Oxford energy dispersive X-ray spectrometer. The gold spray instrument uses the Japanese Hitachi E-1045 ion sputter.

Sample preparation process:

Powder sample: A small amount of sample powder (about $3 \mathrm{mg}$ ) was uniformly dispersed on a sample stage to which conductive paste was adhered, then a $5 \mathrm{~nm}$ thick nano gold particle film was uniformly sprayed on the surface.

Test process: Put the sample stage into the electron microscope
Table 2

Alkali metal content in wheat straw $(\mathrm{mg} / \mathrm{g})$.

\begin{tabular}{lllll}
\hline Element & $\mathrm{K}$ & $\mathrm{Ca}$ & $\mathrm{Na}$ & $\mathrm{Mg}$ \\
\hline Wheat Straw mg/g & 20.89 & 5.89 & 0.64 & 1.49 \\
\hline
\end{tabular}

sample chamber, vacuum. After the vacuum reaches $3 \times 10^{-3} \mathrm{kPa}$, open the electron gun, start to observe the sample, adjust the focal length, different multiples and areas, take pictures.

\section{Results and discussion}

\subsection{Elemental analysis experiment of wheat straw}

Through the microwave digestion experiment, it is found that the alkali metal (in Table 2) in the wheat straw is mainly $\mathrm{K}$ and the content is $20.89 \mathrm{mg} / \mathrm{g}$. Na content is relatively low and is $0.64 \mathrm{mg} / \mathrm{g}$. Because $\mathrm{K}$ is an essential nutrient for plants, which helps plants absorb and balance other elements, regulate air and water circulation, and help plants make and store nutrients. And excess $\mathrm{Na}$ can adversely affect plant growth. The results of this experiment are consistent with the actual situation of biomass.

By the chemical extraction experiments (comparing Fig. 3 and Table 2), the alkali metal occurrence forms in the wheat straw is obtained. The content of WS K is $15.87 \mathrm{mg} / \mathrm{g}$, accounting for $75.08 \%$. The content of NACS $\mathrm{K}$ is $3.36 \mathrm{mg} / \mathrm{g}$, accounting for $16.08 \%$. The content of HS K is $2.78 \%$, and NS K is about $7.93 \%$. The content of WS $\mathrm{Na}$ is $0.27 \mathrm{mg} / \mathrm{g}$, accounting for $42.19 \%$. The content of NACS Na is $0.28 \mathrm{mg} / \mathrm{g}$, accounting for $44.17 \%$. The content of HS Na is $9 \%$, and the content of NS Na is $4.31 \%$. The results show that WS K accounts for the majority of the total amount of $\mathrm{K}$ and there is also considerable NACS K. And Na has a similar occurrence form.

The concentrations of anions and cations in the wheat straw filtrate are shown in Table 3 and Table 4 . The total cationic charge is $13.97 \mathrm{mmol} / \mathrm{L}$ and the total anion charge is $14.09 \mathrm{mmol} / \mathrm{L}$. The total anion and cationic charges are basically conserved and the anion price is slightly higher. This is due to the measurement accuracy limitations and measurement errors of the instrument. The cations are mainly $\mathrm{K}^{+}$and $\mathrm{Ca}^{2+}$ and the anions are mainly $\mathrm{Cl}^{-}$and $\mathrm{NO}_{3}^{-}$. The content of $\mathrm{K}$ is about $80 \%$. According to the ratio of the anion, about $80 \%$ of WS K is $\mathrm{KCl}, 13 \%$ is $\mathrm{KNO}_{3}, 4 \%$ is $\mathrm{K}_{2} \mathrm{SO}_{4}$, and $2 \%$ is $\mathrm{K}_{3} \mathrm{PO}_{4}$. According to the above analysis, it is considered that WS $\mathrm{K}$ in the sample exists as a hydrated ion or a crystal such as $\mathrm{KCl}, \mathrm{KNO}_{3}$,

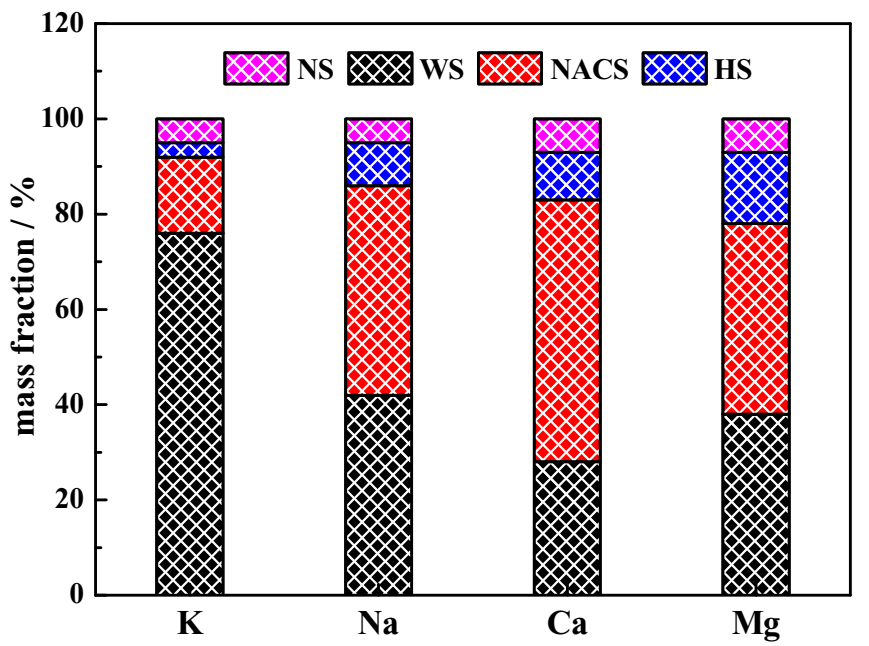

Fig. 3. Occurrence form of alkali (earth) metal in wheat straw. 
Table 3

Anion concentration of wheat straw filtrate.

\begin{tabular}{llllll}
\hline Anion & $\mathrm{SO}_{4}^{2-}$ & $\mathrm{Cl}^{-}$ & $\mathrm{PO}_{4}{ }^{3-}$ & $\mathrm{NO}_{3}^{-}$ & Total charge \\
\hline $\mathrm{Mg} / \mathrm{L}$ & 68.41 & 291.34 & 20.38 & 236.82 & 616.92 \\
$\mathrm{mmol} / \mathrm{L}$ & 0.71 & 8.21 & 0.21 & 3.82 & 14.09 \\
\hline
\end{tabular}

Table 4

Cation concentration of wheat straw filtrate.

\begin{tabular}{llllll}
\hline Cation & $\mathrm{K}^{+}$ & $\mathrm{Na}^{+}$ & $\mathrm{Ca}^{2+}$ & $\mathrm{Mg}^{2+}$ & Total charge \\
\hline $\mathrm{Mg} / \mathrm{L}$ & 396.27 & 6.86 & 46.39 & 14.33 & 436.87 \\
$\mathrm{mmol} / \mathrm{L}$ & 10.16 & 0.30 & 1.16 & 0.60 & 13.97 \\
\hline
\end{tabular}

$\mathrm{K}_{2} \mathrm{SO}_{4}, \mathrm{~K}_{3} \mathrm{PO}_{4}$ or the like. The sample contains a lot of nitrates, which mainly due to excessive application of nitrogen fertilizer during plant growth.

In order to further explore the content and distribution of alkali metals in the samples, the SEM-EDS analysis is carried out. As can be seen from Fig. 4, the contents of $\mathrm{Si}, \mathrm{K}, \mathrm{Ca}, \mathrm{Cl}$ and $\mathrm{Mg}$ are shown. According to the SEM results (face sweep), it is found that $\mathrm{K}, \mathrm{Cl}$ and $\mathrm{Ca}$ are evenly distributed on the surface. Combined with the results of chemical extraction experiments, it is found that most of $\mathrm{K}$ in the wheat straw is WS K and is evenly distributed in the straw. And the uniform distribution of $\mathrm{K}, \mathrm{Cl}, \mathrm{S}$ and $\mathrm{Si}$ at the same position indicates that $\mathrm{K}$ can form $\mathrm{KCl}, \mathrm{K}_{2} \mathrm{SO}_{4}$ and the silicate with $\mathrm{Si}$. This result is consistent with the analysis of the anion and cation concentrations of the wheat straw filtrate. The phenomenon that $\mathrm{Ca}, \mathrm{Mg}$ and $\mathrm{S}$ appear at the same place indicates that $\mathrm{Ca}$ and $\mathrm{Mg}$ exist in the form of $\mathrm{CaSO}_{4}$ and $\mathrm{MgSO}_{4}$.

\subsection{Alkali metals release characteristics during pyrolysis}

Then, the wheat straw was pyrolyzed at different temperatures (at $200^{\circ} \mathrm{C}, 400^{\circ} \mathrm{C}, 600^{\circ} \mathrm{C}, 800^{\circ} \mathrm{C}$ and $1000^{\circ} \mathrm{C}$ ). And the pyrolysis samples were subjected to SEM analysis. It can be seen from Fig. 5 (a) that the wheat straw presented fibrous structure before pyrolysis, and the original microscopic physical structure of the wheat straw remained after being ground and sifted. As shown in Fig. 5 (b), after pyrolysis at $200^{\circ} \mathrm{C}$, the physical structure of the sample was substantially unchanged compared to the original sample. This is because the temperature at $200^{\circ} \mathrm{C}$ does not reach the temperature of the volatile splitting interpretation. And there is mainly the precipitation of water in the sample. As shown in Fig. 5 (c), when the pyrolysis temperature is $400{ }^{\circ} \mathrm{C}$, some tiny holes began to appear on the surface of the sample, and the microscopic structure of the strip fibrous was destroyed and gradually broken. This is mainly because the sample contains many volatiles. At a pyrolysis temperature of $400^{\circ} \mathrm{C}$, a large amount of volatiles are released and the sample structure is thus destroyed. As shown in Fig. 5 (d), when the pyrolysis temperature of $600^{\circ} \mathrm{C}$, there are many holes on the surface of the sample, and the microscopic structure of the fibrous is further damaged, and there are a lot of debris around. This is mainly because as the temperature increases, the release of volatiles is more intense, and the organic matter is thermally cracked, resulting in a more broken sample structure. As shown in Fig. 5 (e), when the pyrolysis temperature is $800^{\circ} \mathrm{C}$, there is some of the melt on the surface of the sample, the basic microstructure destruction. And there are still a lot of debris around, this is mainly because the pyrolysis melting point $800^{\circ} \mathrm{C}$ has reached certain ingredients, such as melting point is $770^{\circ} \mathrm{C}$ of $\mathrm{KCl}$, the sample in the melt. The content of alkali metal $\mathrm{K}$ on the surface showed an increasing trend. As shown in Fig. 5 (f), when the pyrolytic reaches $1000^{\circ} \mathrm{C}$, the surface of the sample is molten and microcosmic physical structure was destroyed.

The pyrolysis samples were subjected to the EDS analysis. And Fig. 6 shows the alkali metal release during the wheat straw pyrolysis at different temperatures. When the temperature is raised from 200 to $400{ }^{\circ} \mathrm{C}$, the release amount of $\mathrm{K}^{+}$is the largest. According to Tables 3 and $4\left(\mathrm{~K}^{+}\right.$concentration is $10.1608 \mathrm{mmol} / \mathrm{L}, \mathrm{NO}_{3}^{-}$ concentration is $3.8197 \mathrm{mmol} / \mathrm{L}$, and $\mathrm{K}^{+}$release amount is $35.5 \%$ ), and $\mathrm{KNO}_{3}$ has a melting point of $334^{\circ} \mathrm{C}$ and the boiling point is $400{ }^{\circ} \mathrm{C}$. When fully pyrolyzed at $400^{\circ} \mathrm{C}, \mathrm{K}^{+}$mainly forms $\mathrm{KNO}_{3}$ with $\mathrm{NO}_{3}^{-}$and a large amount of $\mathrm{K}^{+}$is released in the form of $\mathrm{KNO}_{3}$. When the temperature rises above $600{ }^{\circ} \mathrm{C}_{,} \mathrm{NO}_{3}^{-}$has been consumed and $\mathrm{K}^{+}$begins to be released in the form of $\mathrm{KCl}$.

From the above analysis, it is found that in the process of increasing temperature, $\mathrm{K}^{+}$is first combined with the kind of anions that can form a lower melting inorganic salt. And $\mathrm{K}^{+}$is released as $\mathrm{K}$ salt with this kind of anions and consumes most of these anions. It has been known in the above that biomass (especially crops that are heavily applied with nitrogen fertilizer) will contain more $\mathrm{NO}_{3}^{-}$than coal. And $\mathrm{KNO}_{3}$ is an inorganic salt with a very low boiling point. Therefore, at relatively lower temperatures, the alkali metal in the wheat straw is more easily released than that in the coal, and the amount of release will be larger. And the corrosion problem of the equipment will be more prominent. This is also the reason why the problem of corrosion and slagging is more serious in the process of biomass burning.

Fig. 7 shows the XRD results of samples at different pyrolysis temperatures. It can be seen that the accurate result of XRD measurement is not obtained at $200^{\circ} \mathrm{C}$, which is mainly due to that the organic matter and the bound water are not sufficiently decomposed at this temperature. The organic matter and bound water interferes with XRD detection. When the temperature is raised to $400{ }^{\circ} \mathrm{C}$, most of the bound water is decomposed and much $\mathrm{KCl}$ is produced. When the temperature reached $600^{\circ} \mathrm{C}$, the content of $\mathrm{KCl}$ inside the sample reached the maximum. This is mainly due to the conversion of organic $\mathrm{K}^{+}$to inorganic $\mathrm{K}^{+}$. The temperature continues to increase, and $\mathrm{KCl}$ content is lowered. When the temperature reaches $1000^{\circ} \mathrm{C}, \mathrm{KCl}$ is released in a large amount and the content is drastically decreased. Therefore, inside the sample, $\mathrm{KCl}$ content reaches a peak at about $600^{\circ} \mathrm{C}$.

In the surface of the sample, the content of $\mathrm{K}^{+}$and $\mathrm{Cl}^{-}$shows a different law from the internal content. Fig. 8 shows the content of $\mathrm{K}^{+}$and $\mathrm{Cl}^{-}$on the surface of wheat straw under different pyrolysis temperatures. As the pyrolysis temperature increases, $\mathrm{K}^{+}$and $\mathrm{Cl}^{-}$ on the surface of the sample will exhibit "M"-shaped fluctuations. When the temperature is raised from 200 to $400{ }^{\circ} \mathrm{C}$, the content of $\mathrm{K}^{+}$and $\mathrm{Cl}^{-}$on the surface is greatly increased. This is mainly due to decomposition of a large amount of the bound water at $400^{\circ} \mathrm{C}$. The water will spread outward and carry various ions to the surface of the sample. At this time, the temperature is far from reaching the melting point of $\mathrm{KCl}, \mathrm{K}_{2} \mathrm{SO}_{4}$ and $\mathrm{K}_{3} \mathrm{PO}_{4}$, so the amount of their volatilization is small. These $\mathrm{K}$ salts continue to reach the surface and are enriched, resulting in a large increase in the content of $\mathrm{K}^{+}$ and $\mathrm{Cl}^{-}$on the surface of the sample.

When the temperature is raised to $600^{\circ} \mathrm{C}$, since most of the bound water has been decomposed, it is impossible to carry more ions to the surface of the sample. When the temperature continues to rise, the amount of $\mathrm{KCl}$ released increases. So $\mathrm{K}^{+}$and $\mathrm{Cl}^{-}$content on the surface of the sample are greatly reduced. However, at this time, $\mathrm{KCl}$ content inside the sample appears a peak. When the temperature continues to rise to $700^{\circ} \mathrm{C}$, the volatiles are released in large quantities and the temperature approaches the melting point of $\mathrm{KCl} . \mathrm{K}^{+}$and $\mathrm{Cl}^{-}$content of the inorganic form inside the sample is large and is carried out by volatilization. Therefore, $\mathrm{K}^{+}$and $\mathrm{Cl}^{-}$ content on the surface of the sample is increased.

When the temperature is raised to $800^{\circ} \mathrm{C}$, most of the volatiles 

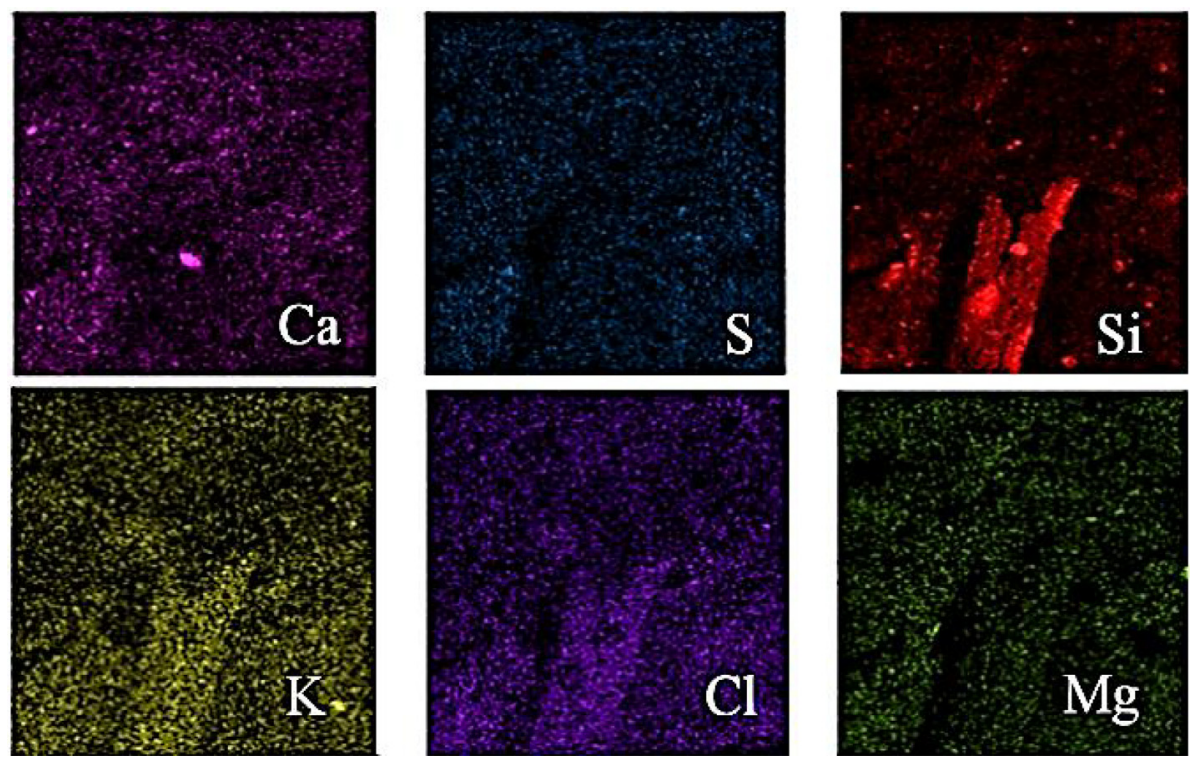

(a). SEM

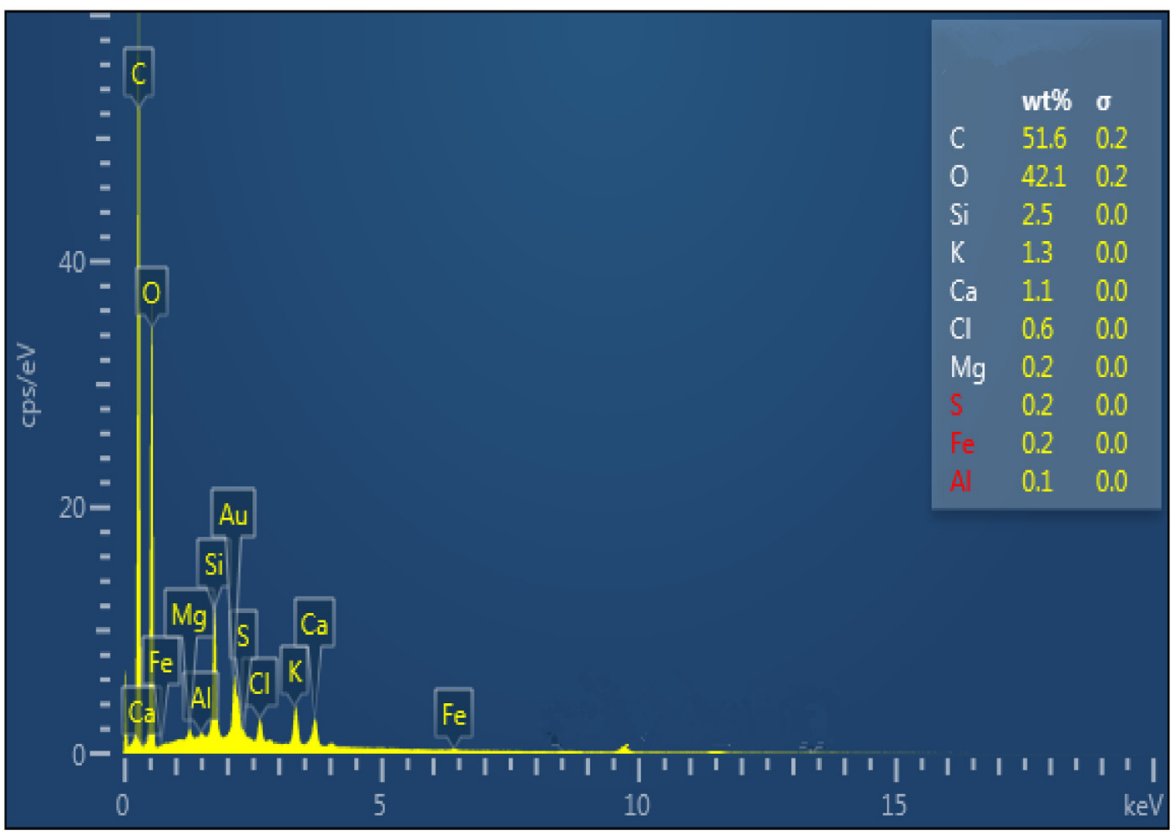

(b). EDS

Fig. 4. SEM-EDS of wheat straw.

have been consumed, and the temperature has exceeded the melting point of $\mathrm{KCl}\left(\right.$ at $\left.770{ }^{\circ} \mathrm{C}\right)$. Part of the $\mathrm{Cl}^{-}$vaporizes in the form of $\mathrm{KCl}$, so $\mathrm{Cl}^{-}$content is reduced. In these conditions, $\mathrm{K}^{+}$in the form of organic matter is still converted to that in the form of inorganic salt, so $\mathrm{K}^{+}$content on the surface of the sample continues to increase. When the temperature is raised to $1000^{\circ} \mathrm{C}$, the release of $\mathrm{KCl}$ is remarkably enhanced, so that $\mathrm{K}^{+}$and $\mathrm{Cl}^{-}$content on the surface of the sample is greatly reduced.

To verify that NACS K can be converted to WS K during pyrolysis, the wheat straw is washed with deionized water for $24 \mathrm{~h}$ to ensure removal of the WS alkali metal in the sample firstly. Then, $3 \mathrm{~g}$ of the water-washed sample is subjected to pyrolysis, and the pyrolyzed sample is washed with deionized water for $24 \mathrm{~h}$ again and then filtered. The concentration of alkali metal ions in the filtrate is as shown in Fig. 9. It can be seen that when the temperature continues to raise, the concentrations of $\mathrm{K}^{+}$and $\mathrm{Na}^{+}$are both stable within a certain range of values. It can be concluded that the NACS alkali metal will be converted to the WS alkali metal during the pyrolysis.

Fig. 10 shows the percentage of different forms of $\mathrm{K}$ in the wheat straw pyrolysis sample at different temperatures. In combination with the above analysis, it can be concluded that at $200^{\circ} \mathrm{C}$, due to the decomposition of the hydrated ionic form $\mathrm{K}$, the $\mathrm{K}$ content in the NACS form decreases and WS $\mathrm{K}$ content increases. At $400^{\circ} \mathrm{C}$, since a large amount of $\mathrm{K}^{+}$is released in the form of $\mathrm{KNO}_{3}$, the total 


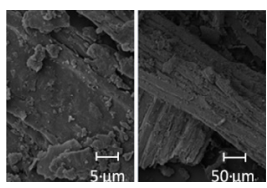

(a) $25^{\circ} \mathrm{C}$

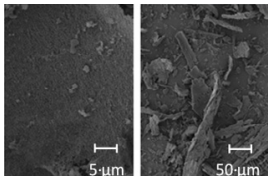

(d) $600^{\circ} \mathrm{C}$

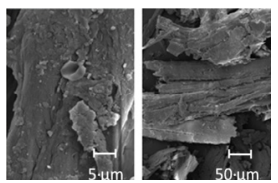

(b) $200^{\circ} \mathrm{C}$

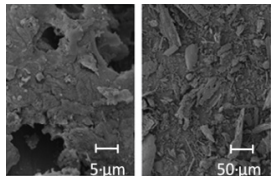

(e) $800^{\circ} \mathrm{C}$

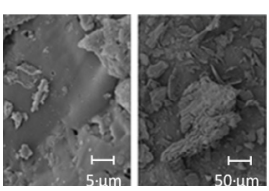

(c) $400^{\circ} \mathrm{C}$

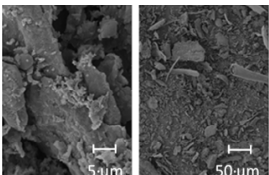

(f) $1000^{\circ} \mathrm{C}$
Fig. 5. Microstructure of pyrolysis samples.

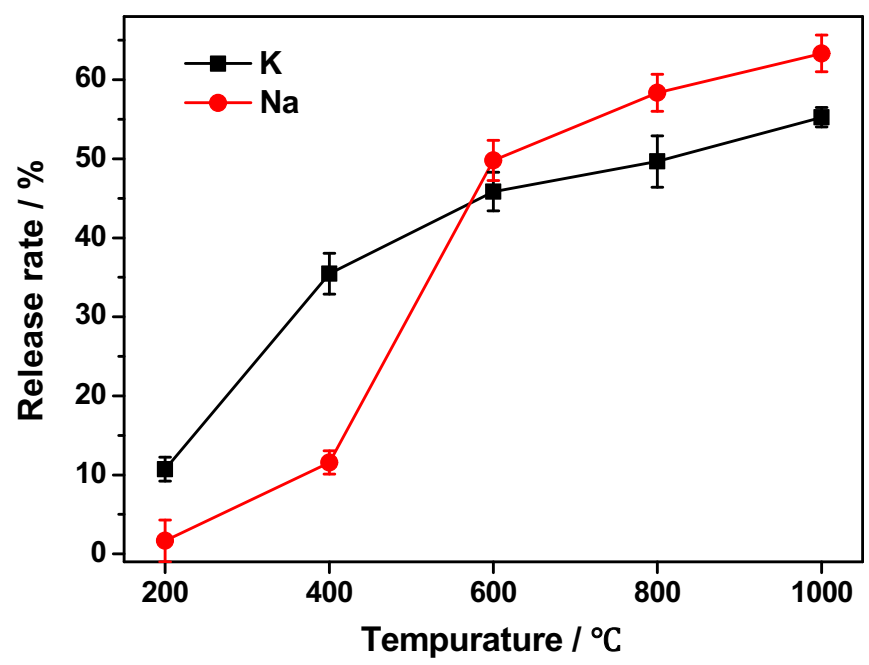

Fig. 6. Alkali metal release rate at different temperatures.

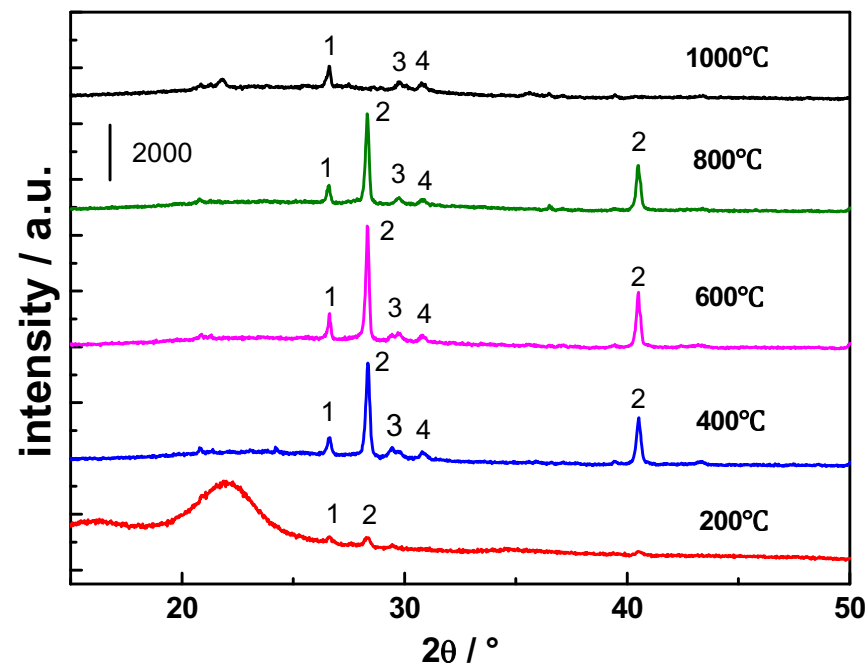

Fig. 7. XRD detection of different pyrolysis temperatures $1 \mathrm{SiO}_{2}$ 2. $\mathrm{KCl} 3 . \mathrm{K}_{2} \mathrm{Si}_{2} \mathrm{O}_{5} 4 . \mathrm{K}_{2} \mathrm{SO}_{4}$

$\mathrm{K}$ content is largely reduced and the relative content of NACS K is increased. Thus, an increase in the ratio of NACS K to WS K results in the reaction of NACS K to WS K to proceed. When the temperature is raised from 400 to $600^{\circ} \mathrm{C}$, NACS K is continuously converted into

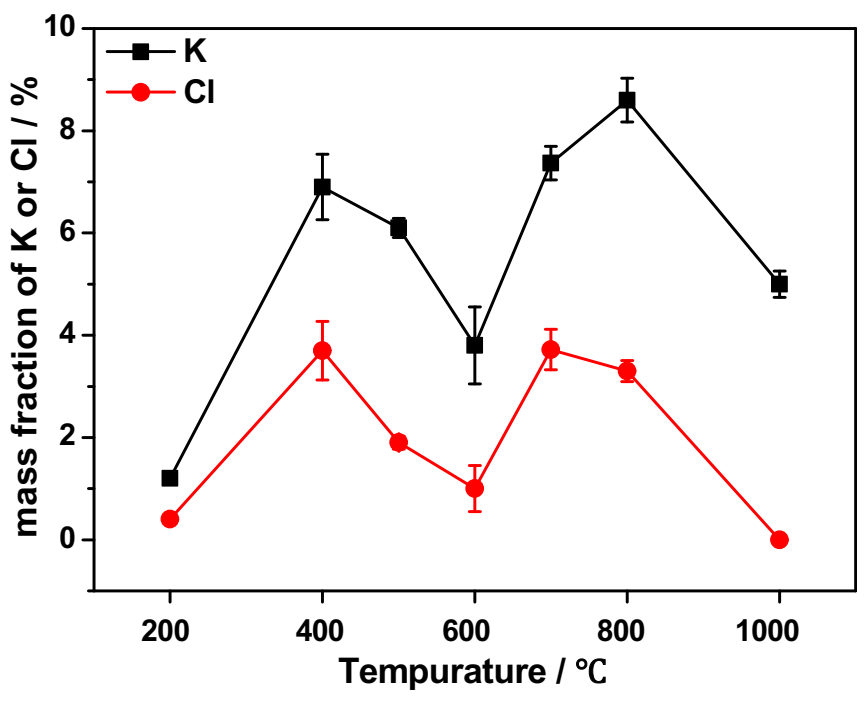

Fig. 8. $\mathrm{K}, \mathrm{Cl}$ content on the sample surface at different temperatures.

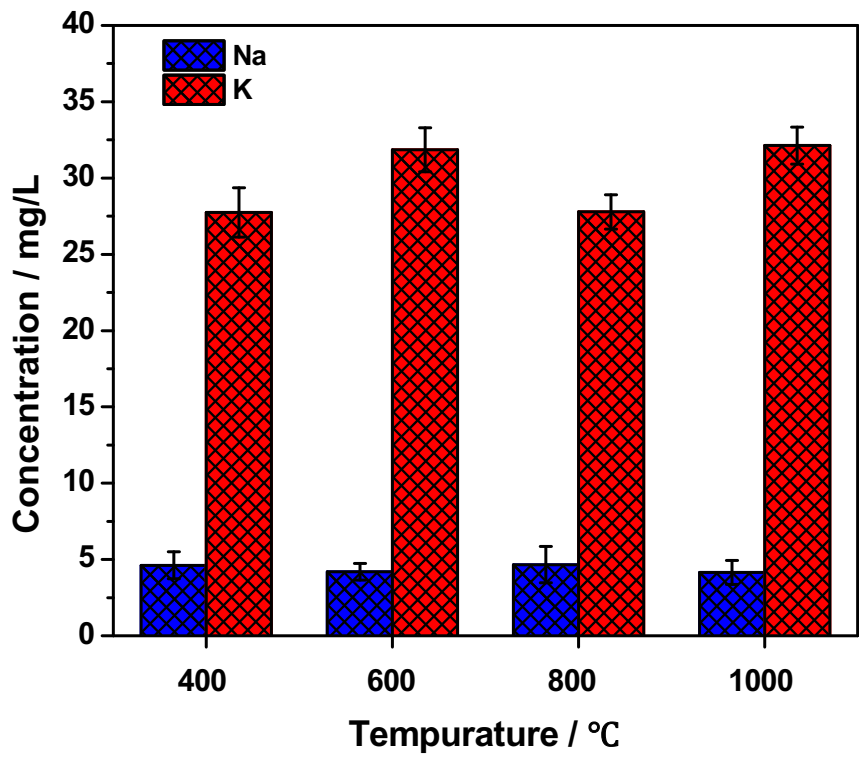

Fig. 9. Conversion of organic alkali metals to water-soluble alkali metals at different pyrolysis temperatures.

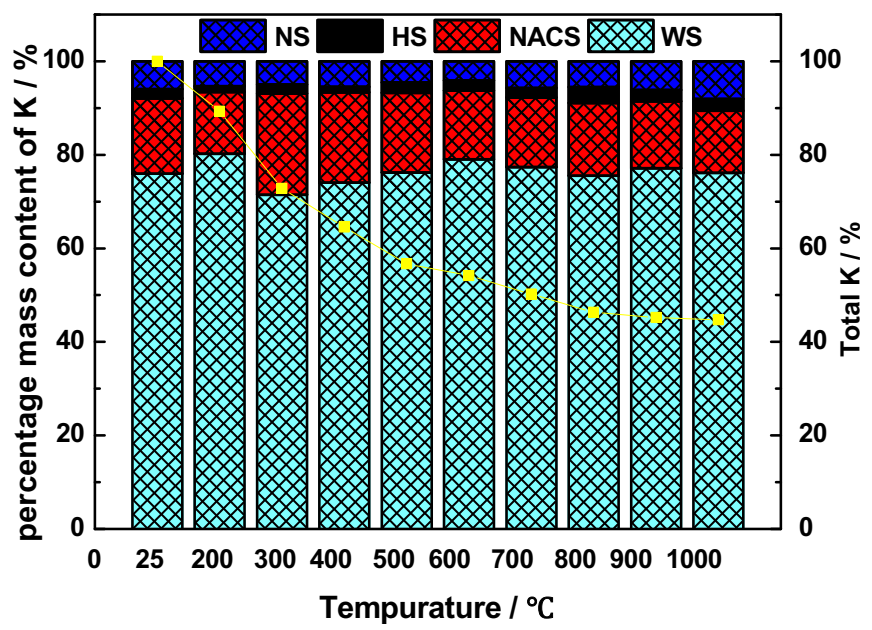

Fig. 10. The occurrence form of $\mathrm{K}$ in the pyrolysis semi-coke of wheat straw. 


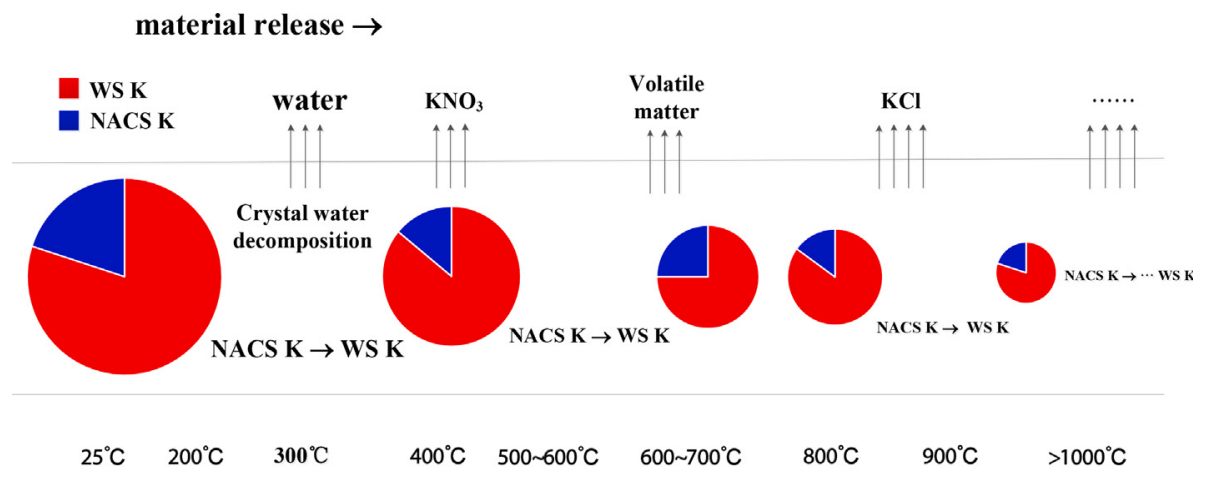

temperature increase $\rightarrow$

Fig. 11. Mechanism of conversion and release of $\mathrm{K}$ with temperature increase.

WS K. So the relative content of NACS K is continuously decreased. The temperature rises from 600 to $800^{\circ} \mathrm{C}$, which reaches the melting point of $\mathrm{KCl}$. WS $\mathrm{K}$ is released in large quantities in the form of $\mathrm{KCl}$, and the relative amount of NACS $\mathrm{K}$ in the form rises again.

Fig. 11 shows the mechanism of conversion and release of $\mathrm{K}$ with temperature increase. As the temperature increases, the crystal water first decomposes and releases, which carries $\mathrm{K}$ and $\mathrm{Cl}$ to the surface of the sample and accompanied with the release of $\mathrm{KNO}_{3}$. When WS $K$ is released, the reaction of NACS K to WS K (NACS $\mathrm{K} \rightarrow$ WS $\mathrm{K}$ ) occurs and will continue until water-soluble $\mathrm{K}$ relative amount rises to a certain value. When the temperature continues to rise to $600{ }^{\circ} \mathrm{C}$, the volatiles begin to release and carry $\mathrm{K}$ and $\mathrm{Cl}$ to the surface of the sample. When the temperature rose to $800^{\circ} \mathrm{C}, \mathrm{KCl}$ begins to release in large quantities. And reaction of NACS K to WS K (NACS $\mathrm{K} \rightarrow$ WS K) occurs again.

From the above analysis, it can be concluded that the process of converting NACS $\mathrm{K}$ into WS $\mathrm{K}$ is a dynamic process. Under certain temperatures, when the ratio of NACS K to WS K exceeds a certain value, NACS $\mathrm{K}$ is converted to WS K. The conversion will continue until the ratio is reduced to this value. As the temperature continues to rise, WS K will vaporize in the form of inorganic salt and the ratio exceeds this value again. Thereafter, NACS K is converted to WS K. Therefore, the elevated temperature drives the conversion of NASC K into WS K and the release of WS K, which is a process of continuous circulation. The process of $\mathrm{K}$ release is always accompanied by the NACS $\mathrm{K} \rightarrow$ WS K reaction.

\section{Conclusion}

In this paper the microwave digestion experiments, chemical extraction experiments, SEM-EDS, XRD, ICP-AES, XPS are applied, and the following conclusions can be drawn:

(1) Through chemical extraction and microwave digestion experiments, it can be found that the alkali metal in wheat straw is mainly $\mathrm{K}$ and the content of WS $\mathrm{K}$ is $75.98 \%$, the content of NACS K is $16.08 \%$, the content of HS K is $2.78 \%$, NS $\mathrm{K}$ is about $7.93 \%$. WS $\mathrm{K}$ in wheat straw is in the form of $\mathrm{KCl}$, $\mathrm{KNO}_{3}, \mathrm{~K}_{2} \mathrm{SO}_{4}, \mathrm{~K}_{3} \mathrm{PO}_{4}$, about $80 \% \mathrm{KCl}, 13 \%$ is $\mathrm{KNO}_{3}, 4 \%$ is $\mathrm{K}_{2} \mathrm{SO}_{4}$, and $2 \%$ is $\mathrm{K}_{3} \mathrm{PO}_{4}$.

(2) During the pyrolysis, $\mathrm{K}$ will release a large amount in the temperature range of $200-400^{\circ} \mathrm{C}$ and $800-1000^{\circ} \mathrm{C}$. At $400{ }^{\circ} \mathrm{C} 35.50 \%$ of $\mathrm{K}$ will release as $\mathrm{KNO}_{3}$. At $600^{\circ} \mathrm{C}$, $\mathrm{K}$ release amount accounts for $45.85 \%$ in $\mathrm{KCl}$ form. When the temperature rises to $800{ }^{\circ} \mathrm{C}$, $\mathrm{K}$ release accounts for $53.66 \%$ of the total. And $\mathrm{K}$ release accounts for $55.26 \%$ at $1000^{\circ} \mathrm{C}$.
(3) It is found that NACS K can convert into WS K when wheat straw is pyrolyzed. When the temperature is raised from 200 to $1000^{\circ} \mathrm{C}$, WS K releases first. When WS K content lowers to a certain extent, NACS K begins to convert to WS K. This reaction proceeds until WS K relative amount rises to a certain value. This phenomenon appears repeatedly with temperatures increasing.

\section{Declaration of competing interest}

The authors declare that they have no known competing financial interests or personal relationships that could have appeared to influence the work reported in this paper.

\section{Acknowledgment}

This work was supported by the National Natural Science Foundation of China (No. 51736010). The authors are also thankful for the suggestions of Pro. Huijun Li in North China Electric Power University on this work.

\section{References}

[1] B.M. Jenkins, L.L. Baxter, T.R. Mile, Combustion properties of biomass, Fuel Process. Technol. 54 (1998) 17-46.

[2] H.P. Nielsen, F.J. Frandsen, K.D. Johansen, The implications of chlorine associated corrosion on the operation of biomass-fired boilers, Prog. Energy Combust. Sci. 26 (2000) 283-298.

[3] Y.T. Cai, W.M. Yang, Z.M. Zheng, M.C. Xu, K.B. Siah, S. Prabakaran, Modelling of ash deposition in biomass boilers: a review, Energy Procedia 143 (2017) 623-628.

[4] B. Seshadri, N.S. Bolan, R. Thangarajan, U. Jena, K.C. Das, H. Wang, R. Naidu, Chapter 5-biomass energy from revegetation of landfill sites, Bioremediation and Bioeconomy (2016) 99-109.

[5] K.G. Sadhan, Biomass \& bio-waste supply chain sustainability for bio-energy and bio-fuel production, Procedia Environmental Sciences 31 (2016) 31-39.

[6] B. Sander, N. HenriKsen, O.H. Larsen, Emissions, corrosion and alkali chemistry in straw-fired combined heat and power plants, in: 1st World Conference on Biomass for Energy and Industry Sevilla Spain, 2000.

[7] J.N. Knudsen, P.A. Jensen, W. Lin, Secondary capture of chlorine and sulfur during thermal conversion of biomass, Energy Fuels 19 (2005) 606-617.

[8] K. Salo, W. Mojtahedi, Fate of alkali and trace metals in biomass gasification, Biomass Bioenergy 15 (1998) 263-267.

[9] Y.Q. Niu, H.Z. Tan, S.E. Hui, Ash-related issues during biomass combustion: alkali-induced slagging, silicate melt-induced slagging (ash fusion), agglomeration, corrosion, ash utilization, and related countermeasures, Prog. Energy Combust. Sci. 52 (2016) 1-61.

[10] J. Sandberg, C. Karlsson, R.B. Fdhila, A 7 yearlong measurement period investigating the correlation of corrosion, deposit and fuel in a biomass fired circulated fluidized bed boiler, Appl. Energy 88 (2011) 99-110.

[11] U. Kleinhans, C. Wieland, F. Frandsen, H. Spliethoff, Ash formation and deposition in coal and biomass fired combustion systems: progress and challenges in the field of ash particle sticking and rebound behavior, Prog. 
Energy Combust. Sci. 68 (2018) 65-168.

[12] F.H. Guo, Z.P. Zhong, Co-combustion of anthracite coal and wood pellets: thermodynamic analysis, combustion efficiency, pollutant emissions and ash slagging, Environ. Pollut. 239 (2018) 21-29.

[13] L.L. Baxter, Influence of ash deposit chemistry and structure on physical and transport properties, Fuel Process. Technol. 56 (1998) 81-88.

[14] H.P. Nielsen, F.J. Frandsen, K.L. Dam-Johansen, The implications of chlorineassociated corrosion on the operation of biomass-fired boilers, Prog. Energy Combust. Sci. 26 (2000) 283-298.

[15] L.M. Romeo, R. Gareta, Fouling control in biomass boilers, Biomass Bioenergy 33 (2009) 854-861.

[16] W. Lin, G. Krusholm, K. Dam-Johansen, Agglomeration Phenomena in Fluidized Bed Combustion of Straw, American Society of Mechanical Engineers, 1997, pp. 831-837.

[17] E. Fewer, Importance of coal ash composition in protecting the boiler against chlorine deposition during combustion of chlorine-rich biomass, Fuel 84 (2005) 201-212.

[18] L. Baxter, T. Miles, T. Miles, The behavior of inorganic material in biomassfired power boilers-field and laboratory experiences: volume ii of alkali deposits found in biomass power plants, Fuel Process. Technol. 54 (1998) 47-78.

[19] A. Agüero, I. Baráibar, M. Gutiérrez, M. Hernández, R. Muelas, S. Rodríguez, Biomass corrosion behavior of steels and coatings in contact with $\mathrm{KCl} / \mathrm{K}_{2} \mathrm{SO}_{4}$ at $550^{\circ} \mathrm{C}$ under an oxy-fuel combustion atmosphere: a screening laboratory test, Surf. Coat. Technol. 350 (2018) 188-200.

[20] L. Baxter, R. Miles, R. Miles, M. Jenkins, T. Milne, D. Dayton, W. Bryers, L. Oden, The behavior of inorganic material in biomass-fired power boilers: field and laboratory experiences, Fuel Process. Technol. 54 (1998) 47-78.

[21] Z.H. Min, Y. Piyachat, A. Mohammad, S. Zhang, C.Z. Li, Catalytic reforming of tar during gasification. Part II. Char as a catalyst or as acatalyst support for tar reforming, Fuel 90 (2011) 2545-2552.

[22] X. Yang, J. Szuhánszki, Y.F. Tian, D. Ingham, L. Ma, M. Pourkashanian, Understanding the effects of oxyfuel combustion and furnace scale on biomass ash deposition, Fuel 247 (2019) 36-46.

[23] G. Mjohamed, N. Aners, O. Marens, Alkali retention/separationduring baggasse gasification: a comparison between a fluided bed and a cyclinegasifier, Biomass and Bionenergy 21 (2001), 461-47.

[24] O. Tsutomu, S. Nozomu, H. Jun-ichiro, Primary release of alkali and alkaline earth metallic species during the pyrolysis of pulverized biomass, Energy Fuels 19 (5) (2005) 2164-2171.

[25] T. Okuno, N. Sonoyama, J.I. Hayashi, C.Z. Li, C. Sathe, T. Chiba, Primary release of alkali and alkaline earth metallic species during the pyrolysis of pulverized biomass, Energy Fuels 19 (2005) 2164-2171.

[26] H. Wu, D.M. Qu, C.Z. Li, Volatilization and catalytic effects of alkali and alkaline earth metallic species during the pyrolysis and gasification of Victorian brown coal. Part III. The importance of the interactions between volatiles and char at high temperature, Fuel 81 (2002) 1033-1039.

[27] Y.F. Liao, G. Yang, X.Q. Ma, Experimental study on the combustion characteristics and alkali transformation behavior of straw, Energy Fuels 26 (2012) 910-916.

[28] A. Pettersson, L.E. Amand, B.M. Steenari, Chemical fractionation for the characterization of fly ashes from co-combustion of biofuels using different methods for alkali reduction, Fuel 88 (2015) 1758-1772.

[29] S. Velizar, G. Milan, B. Dragana, Cross-flow leaching of alkali and alkalineearth metals from sawdust and wheat straw e Modelling of the process, Fuel Process. Technol. 143 (2016) 204-212.

[30] Y.B. Wang, H.Z. Tan, X.B. Wang, The condensation and thermodynamic characteristics of alkali compound vapors on wall during wheat straw combustion, Fuel 187 (2017) 33-42.

[31] R.D. Li, X.P. Kai, T.H. Yang, Y. Sun, Y.G. He, S.Q. Shen, Release and transformation of alkali metals during co-combustion of coal and sulfur-rich wheat straw, Energy Convers. Manag. 83 (2014) 197-202.

[32] D.Y. Wu, Y.H. Wang, Y. Wang, S. Li, X.L. Wei, Release of alkali metals during cofiring biomass and coal, Renew. Energy 96 (2016) 91-97.

[33] Y.Z. Liu, Y. He, Z.H. Wang, J. Xia, K.D. Wan, R. Whiddon, K.F. Cen, Characteristics of alkali species release from a burning coal/biomass blend, Appl. Energy 215 (2018) 523-531.

[34] F. Jonathan, S. Erik, B. Dan, B. Christoffer, Alkali transformation during single pellet combustion of soft wood and wheat straw, Fuel Process. Technol. 143 (2016) 204-212.

[35] B. Zhang, Z.P. Zhong, Z.Y. Xue, J.M. Xue, Y.Y. Xu, Release and transformation of $\mathrm{K}$ in co-combustion of coal and wheat straw in a BFB reactor, Appl. Therm. Eng. 144 (2018) 1010-1016.

[36] S.A. Benson, P.L. Holm, Comparison of inorganics in three low-rank coals, Ind. Eng. Chem. Prod. Res. Dev. 24 (1) (1983) 145-149. 